\title{
Implementation of a group-based physical activity programme for ageing adults with ID: a process evaluation
}

\author{
Marieke van Schijndel-Speet MSc, ${ }^{1,4}$ Heleen M. Evenhuis MD PhD, ${ }^{2}$ Ruud van Wijck $\mathrm{PhD}^{5}$ and \\ Michael A. Echteld PhD ${ }^{3}$ \\ ${ }^{1}$ Researcher, ${ }^{2}$ Professor, ${ }^{3}$ Assistant Professor, Intellectual Disability Medicine, Department of General Practice, Erasmus Medical Center \\ Rotterdam, Rotterdam, The Netherlands \\ ${ }^{4}$ Researcher, Ipse de Bruggen, Zoetermeer, The Netherlands \\ ${ }^{5}$ Researcher, Center for Human Movement Sciences, University Medical Center Groningen, Groningen, The Netherlands
}

\section{Keywords}

evaluation, health promotion,

implementation

\section{Correspondence}

Ms Marieke van Schijndel-Speet

Intellectual Disability Medicine, Department

of General Practice

Erasmus Medical Center Rotterdam

Rotterdam, 3000 CA

The Netherlands

E-mail: m.vanschijndel-speet@erasmusmc.nl

Accepted for publication: 31 March 2014

doi:10.1111/jep.12145

\begin{abstract}
Rationale, aim and objectives This paper describes the results of the process evaluation of a physical activity programme for people with intellectual disabilities (ID), including information about the concepts 'fidelity', 'dose delivered', 'satisfaction' and 'context'.

Methods Qualitative and quantitative methods among participants and programme leaders were used.

Results The programme was well accepted, feasible and applicable to ageing people with ID. It was successfully implemented in terms of fidelity and dose delivered, although differences between day-activity centres were observed.

Conclusions The hampering factors that are revealed in this study and the facilitating activities that were part of the implementation plan may be used by care provider services for (ageing) people with ID and other groups of people with cognitive and/or physical deficits, such as frail elderly people or people with dementia when developing and or preparing implementation of health promotion programmes.
\end{abstract}

\section{Introduction}

As in the general population, health promotion among people with intellectual disabilities (ID) has become an important topic in the light of their unhealthy lifestyles [1-3], lower fitness and bad health conditions [4-8]. This unhealthy status is associated with immobility and higher dependence in performing activities in daily living [9]. Development and adequate evaluation of health promotion programmes are thus rapidly gaining in importance.

Several health promotion programmes have been developed, mainly addressing (younger) adults with mild ID [10-12]. Although the importance and utility of process evaluation have become more widely recognized [13], in most studies, emphasis is placed on the outcome evaluation to determine whether these programmes were successful; process evaluations remain scarce [10,14-16]. Process evaluation is used to monitor and document programme implementation and can aid in understanding the relationship between specific programme elements and programme outcomes [13]. In addition, the process evaluation is about what was learned about the programme's feasibility and prerequisites for implementation, and how that information can be fruitfully applied in the future [17]
Frameworks that guide the development and performance of process evaluation plans mostly include one or more of the following concepts $[13,18,19]$ : 'Fidelity' (implementation of the intervention), 'Dose delivered' (provided elements of the intervention), 'Dose received' (extent to which participants actively engage), 'Satisfaction with the programme', 'Reach' (participation rate, attendance), 'Recruitment' (e.g. maintenance of participant involvement in intervention and measurement components in the study) and 'Context' (aspects of the environment that may have influenced intervention implementation or outcomes).

A physical activity (PA) programme was developed for older adults with ID and implemented in five day-activity centres in three Dutch ID care organizations. This paper describes the results of its process evaluation, including information about the concepts 'fidelity', 'dose delivered', 'satisfaction' and 'context'. Results of the other elements of the process evaluations ('reach', 'recruitment' and 'dose received') have been described elsewhere [20,21]. Research questions of the current paper are:

1 To what extent was the new PA programme implemented as planned during the intervention period and performed compliant to the programme guidelines (fidelity and dose delivered)? 
2 To what extent was the programme feasible and applicable according to the programme leaders and participants (satisfaction)? 3 What aspects of the environment may have had impact on the implementation of the programme during the intervention period (context)?

\section{Methods}

\section{Participants}

PA instructors, together with staff of five day-activity centres, executed the programme in 8 groups of $8-10$ participants.

Eighty-one participants and 65 controls (age 44+) with mild or moderate ID (IQ scores 50-70 and 35-50, respectively) were included after written informed consent was obtained [22]. The participants were judged to have the ability to function in a group. People with dementia or with a medical contraindication for PA or dependent on a wheelchair in-house were excluded. Ethical approval for this study was obtained from the Medical Ethics Committee of the Erasmus University Medical Center (NL29573.078.09). The study adheres to the Declaration of Helsinki for research involving human subjects.

In total, 21 staff members of day-activity centres and $11 \mathrm{PA}$ instructors conducted the PA programme. The staff of day-activity centres knew the participants well and were experienced in conducting the target group in activities provided at the centre (3-21 years of experience). Most of them had some experience in conducting PAs with the target group, such as walking and dancing, or activities while sitting on a chair. The PA instructors were experienced in drafting and conducting PA programmes for older adults with ID (two instructors had 1-year experience; the others had 9-39 years of experience). Most participants were unknown to the instructors. The PA instructors received a 1-day training, including exercises on how to put a training session together in accordance with the programme guidelines.

\section{PA programme}

The guidelines of the American College of Sports Medicine and the American Heart Association [23] were used to develop the PA framework consisting of three PA sessions per week during 8 months. In addition, information was provided about the fitness components that should be trained during each session (endurance, strength, balance and flexibility), as well as duration and intensity of activities during the initiation phase (first 6 weeks), extension (14 weeks) and maintenance phase (12 weeks) [22]. In collaboration with physical therapists and PA instructors, feasible activities were selected and described for each of the selected components: 14 exercises for endurance, 18 for strength, 17 for balance and 6 for flexibility.

Next to education, several behavioural change techniques were used to achieve active participation, including: 'Set graded tasks', 'Provide instruction and model/demonstrate behaviour', 'Provide feedback on performance', 'Mirroring' and 'Prompt rewards contingent on effort or progress towards behaviour and on successful behaviour'. The design of the programme was such that its contents could be tailored to the individual participant [22]

\section{Measurements}

A registration form was developed to gather data about the frequency of the PA sessions as well as the fitness components that were trained during each session and their duration (dose delivered). PA instructors reported directly to the researcher if a PA programme session was cancelled (fidelity).

To gain more in-depth information about the feasibility and applicability of the programme, semi-structured interviews were performed with individual PA instructors. Open-ended questions were formulated about the selection and implementation of feasible PAs, the applicability of the PA framework such as the duration and intensity of activities, and the applied behavioural change strategies to achieve active participation of the target group. At the end of the interview, they could provide additional remarks about the programme and its implementation. In addition, short semistructured interviews with participants were performed to gain insight in their opinion about the PA programme. Participants were asked if they enjoyed or did not enjoy the PA programme and if they would like to continue the programme in the future, or if they would prefer to stop. Two open questions were asked about what they specifically liked and disliked about the PA programme.

A questionnaire was developed for the programme leaders (both PA instructors and staff of day-activity centres) to gain quantitative information about factors that may have had impact on the programme's implementation. Relevant determinants for implementation of innovations described by Fleuren et al. were selected and included characteristics of the programme leaders (including self-efficacy, attitude and support), characteristics of the programme's content, characteristics of the organization (including support of programme leaders by colleagues and superiors and the availability of prerequisites to perform the programme) and characteristics of the socio-political context (willingness of participants to cooperate with the programme) [24]. Subsequently, propositions were formulated and had to be answered on a 5-point Likert-type rating scale: (1) totally disagree; (2) disagree; (3) neither disagree nor agree; (4) agree; and (5) totally agree. The questionnaire ended with an open question for additional comments regarding the programme's implementation.

\section{Procedure}

PA instructors were asked to register for each training session which fitness components were trained, which activities participants performed per fitness component, and the duration of each activity

The written questionnaire was sent to all programme leaders in the sixth month of the intervention period.

Six months after the intervention had stopped, the PA instructors were interviewed. The semi-structured interviews were performed by a PA instructor who has been involved with the programme's execution only at the very beginning of the intervention. She therefore knew the programme well, but was not involved in its performance. In total, seven PA instructors participated in five interviews (one interview was with three PA instructors); all five day-activity centres were represented. The interviewer took notes during the activities and made audio recordings of the interviews. She wrote reports of the interviews afterwards. These reports were 
sent to the interviewees for authorization and they all agreed with the content of the reports.

The interviews with participants were performed by a psychologist or behavioural therapist, working at one of the involved ID care organizations but who was not directly involved in the programme's execution. They were experienced in interviewing people with ID. At forehand, they received some tailored information about the programme and the context in which it was performed to understand the comments of participants. The interviews were part of the effect measurements of the study and thus performed recently after the programme had finished. Participants were considered to be capable of self-report if they used comprehensible speech and could oversee a time frame of at least 1 week. The interviewers took notes during the interview.

\section{Analyses}

Data from programme registration forms, written questionnaires and interviews with participants were entered in a database by support workers working at the ID care organizations. Descriptive analyses were performed with SPSS version 20.

The percentage of cardiovascular training for one group was calculated by dividing the amount of training sessions with cardiovascular activities by the amount of executed training sessions. Balance and strength activities in training sessions were calculated similarly.

The mean duration of cardiovascular, balance and strength activities was calculated by dividing the total duration of each of these activities by the amount of training sessions in which they were included. The researcher analysed the reports of the five interviews with PA instructors by listing all the comments about feasibility and applicability, including factors that, according to the interviewees, may have had an impact on the implementation of the programme.

\section{Results}

\section{Implementation and compliance}

The PA programme guidelines entailed three times a week a PA session for the duration of 8 months (100\%), and 94-97\% of all planned sessions in each group were carried out accordingly. Holidays were the main reason for not carrying out the programme; in three cases, a session was not performed because of the illness of the PA instructor.

The PA framework required cardiovascular endurance activities to be performed three times a week, and both balance and strength training to be performed two times a week. Table 1 shows the percentage training of the three fitness components during the intervention period of 8 months. None of the activity centres were completely compliant with the guidelines. Variation is seen between day-activity centres, especially in the performance of cardiovascular activities (26-95\% compliance).

PA instructors were asked to start performing cardiovascular activities, balance activities and strength activities with a duration of 10, 5 and 10 minutes, respectively. After the end of the initiation phase, the PA instructors were asked to increase the duration of cardiovascular, balance and strength activities to 20-30, 10, and 15 minutes, respectively. The mean training duration of the three
Table 1 Frequency of $\mathrm{CV}$, strength and balance activities in each group

\begin{tabular}{llclll}
\hline $\begin{array}{l}\text { Day-activity } \\
\text { centre }\end{array}$ & Group & Participants & $\begin{array}{l}\mathrm{CV}^{*} \\
\text { exercise } \\
\%\end{array}$ & $\begin{array}{l}\text { Balance }^{\dagger} \\
\text { exercise } \\
\%\end{array}$ & $\begin{array}{l}\text { Strength }^{\dagger} \\
\text { exercise } \\
\%\end{array}$ \\
\hline 1 & A & 9 & 95 & 58 & 47 \\
& B & 11 & 75 & 68 & 67 \\
2 & C & 10 & 78 & 61 & 72 \\
& D & 9 & 94 & 58 & 70 \\
3 & E & 7 & 92 & 42 & 52 \\
4 & F & 5 & 89 & 49 & 56 \\
5 & G & 6 & 38 & 44 & 52 \\
\hline
\end{tabular}

* Framework: $100 \%$ (three times a week).

${ }^{\dagger}$ Framework: 66\% (two times a week).

$\mathrm{CV}$, cardiovascular.

fitness components of both the first 4 months and the last 4 months is presented in Table 2. Regarding the last 4 months, all groups were compliant with the duration guidelines for cardiovascular, strength and balance activities. Specifically, the duration of endurance activities increased in the last 4 months compared with the first 4 months. Data on the intensity of training and compliance with the prescribed intensity in the PA framework will be presented elsewhere [21].

\section{Applicability and feasibility of the programme}

\section{Feasibility of activities}

According to the PA instructors, they succeeded to select feasible activities from the activity book that was developed specifically for this programme [22]. Activities were feasible for the whole group, despite the fact that the physical functioning of the participants within a group varied substantially. To increase feasibility, PA instructors provided tailored instructions and activities, and sometimes split the group up into two subgroups. In collaboration with a staff member of the day-activity centre, the PA instructor ensured that each participant could participate at his or her own level and perform the activity as independently as possible.

\section{Applicability of the PA framework}

PA instructors were aware that often more than one fitness component was trained within one activity. This multifunctionality mostly occurred in cardiovascular activities, such as walking, for which (leg)strength and balance are required.

PA instructors succeeded in increasing the activities in duration and intensity, but not always in accordance with the guidelines. Sometimes, participants' attention span limited the extent to which the duration of activities could be increased. PA instructors experienced that with time, participants improved their skills, which facilitated more intensive participation. However, differences in functional abilities limited the intensity of training; more intensive training could have been achieved with a more homogeneous group, as noted by the PA instructors. Materials such as weights and heavy balls were used to increase the intensity of strength exercises. The 
Table 2 Duration of $C V$, strength and balance activities in each group in months 1-4 and months 5-8

\begin{tabular}{|c|c|c|c|c|c|c|c|c|c|c|}
\hline \multirow[b]{2}{*}{$\begin{array}{l}\text { Day-activity } \\
\text { centre }\end{array}$} & \multirow[b]{2}{*}{ Group } & \multirow[b]{2}{*}{ Participants } & \multicolumn{2}{|c|}{$\begin{array}{l}\text { Total duration per } \\
\text { session (minute) }\end{array}$} & \multicolumn{2}{|c|}{$\begin{array}{l}\text { Duration of } \\
\text { CV (minute) }\end{array}$} & \multicolumn{2}{|c|}{$\begin{array}{l}\text { Duration of } \\
\text { balance (minute) }\end{array}$} & \multicolumn{2}{|c|}{$\begin{array}{l}\text { Duration of } \\
\text { strength (minute) }\end{array}$} \\
\hline & & & $\begin{array}{l}\text { Months } \\
1-4\end{array}$ & $\begin{array}{l}\text { Months } \\
5-8\end{array}$ & $\begin{array}{l}\text { Months* } \\
1-4\end{array}$ & $\begin{array}{l}\text { Months }{ }^{\dagger} \\
\text { 5-8 }\end{array}$ & $\begin{array}{l}\text { Months }{ }^{\ddagger} \\
1-4\end{array}$ & $\begin{array}{l}\text { Months* } \\
5-8\end{array}$ & $\begin{array}{l}\text { Months* } \\
1-4\end{array}$ & $\begin{array}{l}\text { Months } \\
5-8\end{array}$ \\
\hline \multirow[t]{2}{*}{1} & $A$ & 9 & 45 & 49 & 26 & 35 & 17 & 16 & 14 & 15 \\
\hline & B & 11 & 45 & 48 & 26 & 22 & 16 & 22 & 17 & 25 \\
\hline \multirow[t]{2}{*}{2} & C & 10 & 37 & 41 & 19 & 23 & 11 & 10 & 14 & 14 \\
\hline & $\mathrm{D}$ & 9 & 33 & 36 & 18 & 19 & 10 & 10 & 12 & 13 \\
\hline \multirow[t]{2}{*}{3} & $E$ & 7 & 26 & 35 & 15 & 24 & 9 & 13 & 10 & 17 \\
\hline & $\mathrm{F}$ & 5 & 23 & 31 & 13 & 23 & 8 & 10 & 8 & 12 \\
\hline 4 & $\mathrm{G}$ & 6 & 23 & 33 & 15 & 22 & 18 & 21 & 16 & 23 \\
\hline 5 & $\mathrm{H}$ & 9 & 22 & 33 & 13 & 33 & 16 & 19 & 15 & 20 \\
\hline
\end{tabular}

*Framework: 10 minutes per session.

${ }^{\dagger}$ Framework: 20/30 minutes per session.

FFramework: 5 minutes per session.

${ }^{\S}$ Framework: 15 minutes per session.

$\mathrm{CV}$, cardiovascular.

availability of a gymnasium increased the variability in choice of cardiovascular activities and facilitated active participation.

\section{Important strategies for active participation of participants}

Demonstration of behaviours, tailoring and positive encouragement were thought to be very effective strategies, even prerequisites, for active participation. Some remarks of PA instructors: 'You have to be very enthusiastic and participate in the activities as a role model to get the participants on their feet and willing to do their very best. Sometimes I could only motivate the participant to run if I gave him a hand and run together with him.' 'Using humor was also motivating. For example giving a "wrong" demonstration of the activity; it provides a good atmosphere and a lot of fun.' Challenging was not only to get participants started, but also to keep them active during the whole session. 'Sometimes if you give your attention to an individual participant, the others become less active. Performing the activities together with a staff member of the day-activity centers really helped to get the participants active for a longer time.'

Furthermore, the techniques 'mirroring', 'prompting rewards' and 'set graded tasks' were supportive according to the PA instructors. 'Seeing group mates being active stimulates being active yourself.' 'Participants were really proud of the badge and medals they received during the programme.' Repetition of the activities improved recognition, so the participants knew what to do and improved their skills, which again was really motivating according to the PA instructors. In addition, a fixed structure of the programme provided recognition and made participants feel secure; they knew what to expect. Sometimes, PA instructors made activities extra fun, for example, by using a football during the walking activity, putting on music during specific activities, throwing a dice during strength activities to establish how many repetitions participants had to make, involving the participants in creating new exercises, offering the exercises in a relevant theme, for example, 'throwing snowballs' in the winter.

PA instructors were not convinced about the added value of the information provided in the education programme about conse- quences of healthy behaviour in general. Not all participants had the ability to learn about this rather abstract concept, even though the exercises within the education programme were really practical and experience based. They were more enthusiastic about the included exercises in the education programme aimed at body awareness and the physical reaction on activity, and discussion about barriers such as fear of falling. During the PA programme, the staff of day-activity centres repeated what was learned during the education programme. Putting what was discussed during the education programme into practice worked very well for participants.

\section{Satisfaction of participants}

Twenty of 66 participants who completed the intervention study were able to be interviewed. Other participants did not have the cognitive ability to answer questions about the programme or were judged by their caregivers to be burdened by participating in the interview. Of the 20 participants who were interviewed after the intervention period ended, 19 mentioned they enjoyed the PA programme and 18 would be willing to continue the programme. In additional remarks, they mentioned the positive atmosphere during the programme and the rewards they had received (medals, diploma). They also mentioned the PAs they liked, such as walking and dancing with the Nintendo WII, and game-like activities such as throwing the ball. In addition, they enjoyed doing activities together with the PA instructor or staff of day-activity centres. Two participants mentioned that they did not enjoy putting on the heart rate monitor each session. One participant noted that she found the activities sometimes intensive and that she did not like to sweat. One participant with mild ID mentioned that she would prefer more variation in the programme: she got bored of the repetition of the activities.

\section{Environmental factors that may have had impact on the programme's implementation}

We received 8 out of 10 and 17 out of 20 completed questionnaires from the PA instructors and staff of day-activity centres, 
Table 3 Mean evaluation scores (1-5) of factors that may have had impact the programme's implementation, from the perspective of PA instructors $(n=8)$ and staff of DC $(n=17)$

\begin{tabular}{|c|c|c|}
\hline & PA instructor & Staff DC \\
\hline \multicolumn{3}{|l|}{ Attitude PA } \\
\hline I enjoy being physically active. & 5.0 & 4.7 \\
\hline I think regular physical activity is important for my clients. & 4.9 & 4.8 \\
\hline Conducting physical activities is part of my job responsibilities. & 4.3 & 3.9 \\
\hline Conducting physical activities is in conflict with my other duties. & 2.0 & 2.7 \\
\hline $\begin{array}{l}\text { I am motivated to continue the physical activity programme at the day-activity centre } \\
\text { after the intervention period has ended. }\end{array}$ & 4.1 & 4.0 \\
\hline My colleagues think regular physical activity is important for my clients. & 4.6 & 4.4 \\
\hline \multicolumn{3}{|l|}{ Self-efficacy } \\
\hline I have sufficient knowledge at my disposal to perform the programme well. & 4.5 & 4.0 \\
\hline I have sufficient skills at my disposal to perform the programme well. & 4.5 & 4.5 \\
\hline I feel confident about my competence to perform the programme well. & 4.5 & 4.2 \\
\hline \multicolumn{3}{|l|}{ Support } \\
\hline My colleagues support me in performing the programme. & 4.0 & NA \\
\hline Collaboration between PA instructors and staff of day-activity centres is good. & 4.4 & 4.5 \\
\hline My superior supports me in performing the programme. & 3.9 & 4.0 \\
\hline \multicolumn{3}{|l|}{ Characteristics of the organization (context) } \\
\hline The available PA materials are sufficient to perform the programme well. & 3.5 & NA \\
\hline The available accommodations are feasible to conduct the activities. & 3.0 & NA \\
\hline The available personnel is enough to prepare and perform the programme well. & 3.4 & 3.9 \\
\hline One or two involved programme leaders coordinate its implementation. & 3.4 & NA \\
\hline \multicolumn{3}{|l|}{ Willingness of participants to cooperate } \\
\hline Participants participate actively in the programme. & 3.9 & 4.3 \\
\hline Participants enjoy participating in the programme. & 4.3 & 4.4 \\
\hline
\end{tabular}

DC, day-activity centre; NA, not applicable; PA, physical activity.

respectively (one PA instructor and one staff member of a dayactivity centre did not work at the ID care provider services anymore). Both PA instructors and staff of day-activity centres do have a positive attitude towards PA. However, staff of day-activity centres do sometimes feel that conducting physical activities conflicts with their other tasks (see Table 3). The PA instructors and staff of day-activity centres were self-confident about their knowledge, skills and competence in executing the PA programme. They also found the programme attractive to execute and were motivated to continue executing the programme after the intervention period would stop.

PA instructors were less satisfied with the requirements to conduct the programme well. In particular, the setting was often not optimal. In two day-activity centres there was no gymnasium available, and the available locations for the activities were not very suitable for this purpose, especially for performing cardiovascular activities. The other day-activity centres did not have a gymnasium at their disposal three times a week, but one or two times a week. Although a gymnasium is not a requirement to get participants physically active, it helps challenging participants to be more active according to the PA instructors, especially for cardiovascular activities.

PA instructors and staff of day-activity centres were positive about their collaboration and felt supported by their colleagues and superiors. According to them, clients participated rather actively in the programme and enjoyed participation.

In addition, we asked the programme's performers if there were other important factors that may have had impact on the implementation of the programme. Logistic problems limited available time for the PA programme. In two day-activity centres, PA instructors had to travel a substantial time (half an hour) to the day-activity centre within a very tight schedule. Furthermore, putting on the heart rate monitors was a time-consuming activity, especially at the start of the programme. Later on, the staff of day-activity centres started putting on the heart rate monitors just before the PA programme started. Finally, the composition of non-homogeneous groups was mentioned as a barrier for (more) intensive participation.

We calculated the mean scores of factors that, according to the programme leaders, may have had a negative impact on the implementation of per day-activity centre (see Table 4). These include (1) the (non)availability of a gymnasium; (2) travel distances of PA instructor; (3) materials; (4) available spaces for exercise; (5) available personnel; (6) coordination; (7) support of a superior; and (8) active participation. Day-activity centres without a gymnasium nearby scored worse on available accommodations and had the lowest per cent of cardiovascular training (see Table 1). In the day-activity centres in which the PA instructor had to travel a substantial distance, leaders were more negative about the availability of personnel and the total duration per PA session was shorter (see Table 2).

\section{Discussion}

In this study, the PA programme for older adults with ID was evaluated in terms of compliance (fidelity), implementation (dose delivered), satisfaction with the programme's content (feasibility 
Table 4 Mean evaluation scores (1-5) per day-activity centre of factors that, according to the PA instructors and staff of day-activity centres, may have had impact on the programme's implementation

\begin{tabular}{|c|c|c|c|c|c|c|}
\hline Day-activity centre & Materials & $\begin{array}{l}\text { Available } \\
\text { accommodations }\end{array}$ & $\begin{array}{l}\text { Available } \\
\text { personnel }\end{array}$ & Coordination & $\begin{array}{l}\text { Support } \\
\text { superior }\end{array}$ & $\begin{array}{l}\text { Active } \\
\text { participation }\end{array}$ \\
\hline $\begin{array}{l}1 \\
\text { Gymnasium } \\
\text { Short travel time instructors }\end{array}$ & 3 & 3 & 3.5 & 4.5 & 4.5 & 3 \\
\hline $\begin{array}{l}2 \\
\text { Gymnasium } \\
\text { Long travel time instructors }\end{array}$ & 3.5 & 4.5 & 4.5 & 3.5 & 4.5 & 4.5 \\
\hline $\begin{array}{l}3 \\
\text { Gymnasium } \\
\text { Short travel time instructors }\end{array}$ & 4 & 2.7 & 3 & 3 & 3 & 4.3 \\
\hline $\begin{array}{l}4 \\
\text { No gymnasium } \\
\text { Long travel time instructors }\end{array}$ & 3 & 1 & 2 & 2 & 4 & 3 \\
\hline $\begin{array}{l}5 \\
\text { No gymnasium } \\
\text { Long travel time instructors }\end{array}$ & 3 & 1 & 2 & 2 & 4 & 3 \\
\hline
\end{tabular}

PA, physical activity

and applicability) and environmental factors that may have had impact on the implementation of the programme (context). Overall, both leaders and participants were enthusiastic about the programme and were willing to continue performing it. PA instructors found the programme feasible for the target group and used all behavioural strategies to improve active participation, including: 'Set graded tasks', 'Provide instruction and model/demonstrate behaviour', 'Provide feedback on performance', 'Mirroring' and 'Prompt rewards contingent on effort or progress towards behaviour and on successful behaviour'. However, differences were observed in the extent to which the PA instructors complied to the programme guidelines (dose delivered). Specifically, a substantial variation was seen in inclusion of cardiovascular activities into the programme, which is also correlated with the attained heart rate levels of participants during the programme [21]. Programme leaders reported factors that may have influenced the programme's compliance: (1) the absence of a gymnasium; (2) travel distances of PA instructors; and (3) the heterogeneity of the groups in terms of participants' physical functioning.

For this study, we formulated a minimum of inclusion criteria, resulting in a heterogeneous study population that reflects clinical practice and thus permits generalization of feasibility. Although the study is performed in the Netherlands, we have no reasons to assume that other results will be found for feasibility in other Western countries. Regarding applicability, it is important that several prerequisites are fulfilled including the availability of a PA expert to draft and conduct the PA programme in concordance with its guidelines and/or to coach staff of day-activity centres - work settings to conduct the programme safely. Secondly, materials and a gymnasium or at least a large accommodation with adequate safety precautions are needed to stimulate active participation and increased heart rates. Physical activities can also be performed outside, but uneven surfaces and bad weather conditions may pose safety threats. If these conditions are fulfilled, we assume that the results about the programme's applicability may be generalized internationally.
One of the strengths of this study was the multifaceted implementation plan [22]. For example, managers and professionals were involved with the development and preparation of the implementation from the very beginning, resulting in a good fidelity. Furthermore, the positive findings about the content and feasibility of the programme are a result of this careful developing process, using the concepts of Intervention Mapping [25]. Further strengths include the use of triangulation: programme leaders and participants were involved in the process evaluation and both qualitative and quantitative methods have been used to gain valid information about the implementation of and satisfaction with the programme. The programme's execution has been monitored during the whole intervention period for each session, which means that detailed and valid information about the 'dose-delivered' was available.

Limitations of this study include the absence of detailed information about the implementation of behavioural strategies. For example, we are not able to draw conclusions about the extent to which the behavioural strategies are performed because we did not monitor it nor prescribe detailed guidelines. In addition, we do not know (yet) whether the indicated negative factors and/or noncompliance of the guidelines have indeed negatively influenced the programme's impact on the health outcomes. However, noncompliance may have contributed to the programme's success in terms of acceptance and client dropout. We do not have data on this proposed relationship.

\section{Conclusion}

The importance of process evaluations is threefold: (1) it may indicate whether a programme's implementation will be successful; (2) it may show aspects that may lead to a programme's improvement; and (3) it may reveal mechanisms of a programme's effectiveness. The current process evaluation contributed to all three aspects of knowledge. The programme was well accepted, feasible and applicable to ageing people with ID. It was successfully implemented in terms of fidelity and showed that behavioural 
change techniques may possibly improve the programme's effectiveness. Environmental factors may be important in successful implementation regarding the compliance with the framework. The hampering factors that are revealed in this study and the facilitating activities that were part of the implementation plan may be used by care provider services for (ageing) people with ID when developing and or preparing implementation of health promotion programmes. As O'Connor-Fleming put it: 'The field of health promotion can only move forward when outcomes of comprehensive evaluations of what does work and what does not work are made available to practitioners' [17]. Further research is needed to evaluate the preconditions for embedding the PA programme into daily practice.

\section{Acknowledgements}

The authors thank The Netherlands Organisation for Health Research and Development (nr 57000003) and the participating Dutch care providers Ipse de Bruggen at Zoetermeer, Abrona at Huis ter Heide and Amarant at Tilburg for their financial support. We are grateful to all CEOs, professionals, and middle managers and clients of Ipse de Bruggen, Abrona and Amarant for their substantial contribution to the development, implementation and evaluation of the physical activity programme.

\section{References}

1. Hilgenkamp, T. I. M., Reis, D., van Wijck, R. \& Evenhuis, H. M. (2012) Physical activity levels in older adults with intellectual disabilities are extremely low. Research in Developmental Disabilities, 33 (2), 477-483.

2. Peterson, J. J., Janz, K. F. \& Lowe, J. B. (2008) Physical activity among adults with intellectual disabilities living in community settings. Preventive Medicine, 47 (1), 101-106.

3. Humphries, K., Traci, M. A. \& Seekins, T. (2009) Nutrition and adults with intellectual or developmental disabilities: systematic literature review results. Intellectual and Developmental Disabilities, 47 (3), 163-185.

4. Hilgenkamp, T. I. M., van Wijck, R. \& Evenhuis, H. M. (2012) Low physical fitness levels in older adults with ID: results of the HA-ID study. Research in Developmental Disabilities, 33 (4), 1048-1058.

5. Hermans, H., Beekman, A. T. \& Evenhuis, H. M. (2013) Prevalence of depression and anxiety in older users of formal Dutch intellectual disability services. Journal of Affective Disorders, 144 (1-2), 94-100.

6. de Winter, C. F., Bastiaanse, L. P., Hilgenkamp, T. I., Evenhuis, H. M. \& Echteld, M. A. (2011) Overweight and obesity in older people with intellectual disability. Research in Developmental Disabilities, 33 (2), 398-405.

7. McCarron, M., Swinburne, J., Burke, E., McGlinchey, E., Carroll, R. \& McCallion, P. (2013) Patterns of multimorbidity in an older population of persons with an intellectual disability: results from the intellectual disability supplement to the Irish longitudinal study on aging (IDS-TILDA). Research in Developmental Disabilities, 34 (1), 521527.

8. Schoufour, J. D., Mitnitski, A., Rockwood, K., Evenhuis, H. M. \& Echteld, M. A. (2013) Development of a frailty index for older people with intellectual disabilities: results from the HA-ID study. Research in Developmental Disabilities, 34 (5), 1541-1555.

9. Hilgenkamp, T. I., van Wijck, R. \& Evenhuis, H. M. (2011) (Instrumental) activities of daily living in older adults with intellectual disabilities. Research in Developmental Disabilities, 32 (5), 1977 1987.

10. Bartlo, P. \& Klein, P. J. (2011) Physical activity benefits and needs in adults with intellectual disabilities: systematic review of the literature. American Journal of Intellectual and Developmental Disabilities, 116 (3), 220-232.

11. Humphries, K., Traci, M. A. \& Seekins, T. (2008) Nutrition education and support program for community-dwelling adults with intellectual disabilities. Intellectual and Developmental Disabilities, 46 (5), 335345 .

12. Marks, B., Sisirak, J. \& Heller, T. (2010) Exercise and Nutrition Health Education Curriculum for Adults with Developmental Disabilities. Philadelphia: Brookes Publishing.

13. Saunders, R. P., Evans, M. H. \& Joshi, P. (2005) Developing a processevaluation plan for assessing health promotion program implementation: a how-to guide. Health Promotion Practice, 6 (2), 134-147.

14. Mann, J., Zhou, H., McDermott, S. \& Poston, M. B. (2006) Healthy behavior change of adults with mental retardation: attendance in a health promotion program. American Journal of Mental Retardation, $111(1), 62-73$.

15. Heller, T., McCubbin, J. A., Drum, C. \& Peterson, J. (2011) Physical activity and nutrition health promotion interventions: what is working for people with intellectual disabilities? Intellectual and Developmental Disabilities, 49 (1), 26-36.

16. Stanish, H. I., Temple, V. A. \& Frey, G. C. (2006) Health-promoting physical activity of adults with mental retardation. Mental Retardation and Developmental Disabilities Research Reviews, 12 (1), 13-21.

17. O'Connor-Fleming, M. L., Parker, E., Higgins, H. \& Gould, T. (2006) A framework for evaluating health promotion programs. Health Promotion Journal of Australia: Official Journal of Australian Association of Health Promotion Professionals, 17 (1), 61-66.

18. Baranowski, T. \& Stables, G. (2000) Process evaluations of the 5-aday projects. Health Education and Behavior, 27 (2), 157-166.

19. Glasgow, R. E. (2006) RE-AIMing research for application: ways to improve evidence for family medicine. Journal of the American Board of Family Medicine, 19 (1), 11-19.

20. van Schijndel-Speet, M., Evenhuis, H. M., van Wijck, R. \& Echteld, M. A. (2014) Results of a Cluster Randomized Clinical Trial show that an evidence-based Physical Activity Program for Older adults with Intellectual Disabilities is effective (submitted).

21. van Schijndel-Speet, M., van den Dorpel, A., Hilgenkamp, T. I. M., Evenhuis, H. M., van Wijck, R. \& Echteld, M. A. (2014) Heart rate response to a physical-activity program among people with intellectual disabilities and its association with improvement in aerobic performance (submitted).

22. van Schijndel-Speet, M., Evenhuis, H. M., van Empelen, P., van Wijck, R. \& Echteld, M. A. (2013) Development and evaluation of a structured programme for promoting physical activity among seniors with intellectual disabilities: a study protocol for a cluster randomized trial. BMC Public Health, 13 (1), 746.

23. Nelson, M. E., Rejeski, W. J., Blair, S. N., et al. (2007) Physical activity and public health in older adults: recommendation from the American College of Sports Medicine and the American Heart Association. Medicine and Science in Sports and Exercise, 39 (8), 14351445.

24. Fleuren, M., Wiefferink, K. \& Paulussen, T. (2004) Determinants of innovation within health care organizations: literature review and Delphi study. International Journal for Quality in Health Care, 16 (2), 107-123.

25. Bartholomew, L. K., Parcel, G. S. \& Kok, G. (1998) Intervention mapping: a process for developing theory- and evidence-based health education programs. Health Education and Behavior, 25 (5), $545-563$. 